\title{
O ENSINO-APRENDIZAGEM DE PLAc PARA ADOLESCENTES HAITIANOS
}

\author{
LA ENSEÑANZA-APRENDIZAJE DE PLAC PARA LOS ADOLESCENTES \\ HAITIANOS
}

THE TEACHING-LEARNING OF PHL FOR HAITIAN ADOLESCENTS

\author{
Danaine Gricélias de MORAIS ${ }^{1}$ \\ Suelene Vaz da SILVA ${ }^{2}$
}

RESUMO: Este estudo de caso qualitativo tem como foco o processo ensino-aprendizagem de português na perspectiva de língua de acolhimento (PLAc). O suporte teórico inclui estudos sobre o fluxo migratório, especialmente para o Brasil, e sobre o ensino de português como parte da acolhida humanitária. O contexto é uma turma de PLAc, cujas aulas ocorreram em 2018 e 2019. Os participantes são 3 adolescentes, imigrantes haitianos, e a professora deles. Os dados foram gerados a partir de plano de aula, material didático, exercício escrito, questionário e o diário reflexivo da professora. Os resultados mostram que as aulas de PLAc contribuíram para o aprimoramento da compreensão e produção escrita e que a aprendizagem se estrutura na relação afetiva entre os alunos e a professora. Para a professora, a experiência com a docência em contexto de PLAc ampliou-lhe os horizontes para um processo ensino-aprendizagem que acolhe e promove a integração do imigrante.

PALAVRAS-CHAVE: Ensino-aprendizagem de PLAc. Imigrante haitiano. Adolescente. Acolhimento.

RESUMEN: Este estudio de caso cualitativo se centra en el proceso de enseñanza-aprendizaje del portugués desde la perspectiva del idioma anfitrión (PIA). El soporte teórico incluye estudios sobre el flujo migratorio, especialmente a Brasil, y sobre la enseñanza del portugués como parte de la recepción humanitaria. El contexto es una clase PIA, cuyas clases se llevaron a cabo en 2018 y 2019. Los participantes son 3 adolescentes, inmigrantes haitianos y su maestra. Los datos se generaron a partir del plan de lección, material didáctico, ejercicio escrito, cuestionario y diario reflexivo del docente. Los resultados muestran que las clases de PIA contribuyeron a la mejora de la comprensión y la producción escrita y que el aprendizaje se estructura en la relación afectiva entre el alumno y el profesor. Para la docente, la experiencia de la docencia en el contexto PIA ha ampliado sus horizontes para un proceso de enseñanza-aprendizaje que acoge y promueve la integración del inmigrante.

PALABRAS CLAVE: Enseñanza-aprendizaje de PIA. Inmigrante haitiano. Adolescente. Recepción.

\footnotetext{
${ }^{1}$ Instituto Federal de Goiás (IFG), Goiânia - GO - Brasil. Licenciada em Letras: Língua Portuguesa. ORCID: https://orcid.org/0000-0002-5491-9587. E-mail: danymorais50@gmail.com

${ }^{2}$ Instituto Federal de Goiás (IFG), Goiânia - GO - Brasil. Professora EBTT. Departamento de Áreas Acadêmicas I. ORCID: https://orcid.org/0000-0001-7400-0212. E-mail: suelene.silva@ifg.edu.br
} 
ABSTRACT: This qualitative case study focuses on the teaching-learning process of Portuguese from the perspective of hosting language (PHL). The theoretical support includes studies on the migratory flow, especially to Brazil and on the teaching of Portuguese as part of the humanitarian reception. The context is a PHL class, whose classes took place in 2018 and 2019. The participants are 3 teenagers, Haitian immigrants, and their teacher. Data were generated from the lesson plan, teaching material, written exercise, questionnaire, and the teacher's reflective diary. The results present that PHL teaching contributed to the improvement of reading and writing skills and that learning is structured in the affective relationship between students and their teacher. For the teacher, the experience with teaching in PHL context has broadened her horizons for a teaching-learning process that hosts and promotes the integration of the immigrant.

KEYWORDS: Teaching-learning of PHL. Haitian immigrant. Adolescent. Hosting.

\section{Introdução}

O fenômeno da migração é entendido, desde os tempos remotos, como os deslocamentos de indivíduos entre espaços geográficos distintos, com o objetivo de se estabelecer em outro lugar, de forma temporária ou permanente. Nesse sentido, o termo migração está intrinsecamente associado ao direito humano de ir e vir a qualquer parte do mundo, e encontrase amparado na Declaração dos Direitos Humanos de 10 de dezembro de 1948 (ILLES; SOUSA, 2012), contudo, esse deslocamento nem sempre ocorre por vontade do sujeito de se domiciliar em um novo território.

Segundo o Alto Comissariado das Nações Unidas para Refugiados Tendências Globais (ACNUR), há cerca de 80 milhões de pessoas deslocadas de suas regiões de origem. Esse número elevado de deslocamentos, principalmente para outros locais fora das fronteiras de seus territórios de origem, tem por causa, na maioria dos casos, conflitos advindos de guerras desencadeadas por governos ditatoriais, como as ocorridas nas regiões da Síria, país responsável por 13,2 milhões de pessoas em condição de migração para outros países (ACNUR, 2020a).

Esses sujeitos são considerados refugiados quando as razões dos deslocamentos atendem aos requisitos postos pela Convenção das Nações Unidas, de julho de 1951 (ONU, 1951), e ampliado pelo Protocolo relativo ao Estatuto dos Refugiados, em dezembro de 1967 (ONU, 1967). Logo, imigrantes em situação de refúgio

[s]ão pessoas que estão fora de seu país de origem devido a fundados temores de perseguição relacionados a questões de raça, religião, nacionalidade, pertencimento a um determinado grupo social ou opinião política, como também devido à grave e generalizada violação de direitos humanos e conflitos armados (ACNUR, 2020b, s/p). 
A este status de migração forçada somou-se a acolhida humanitária, uma modalidade de entrada nos países de destino que amplia a perspectiva dessa forma de deslocamento para inserir pessoas vítimas de outras formas de tragédias, como catástrofes naturais, a exemplo dos haitianos, vítimas diretas ou indiretas do terremoto ocorrido em 2010, ou de violências sociais, como, por exemplo, pobreza extrema, tráfico de pessoas e trabalho escravo, construtos já presentes na categoria 'violação dos direitos humanos', mas que dada a urgência da acolhida, precisavam de regulamentação menos burocrática à exigida ao pedido de refúgio (FERNANDES; FARIA, 2017).

A Lei de Migração - Lei n 13.445, de 24 de maio de 2017 - (BRASIL, 2017) traz um novo olhar para o fenômeno da migração, em relação à Lei n 6.815/1980 (BRASIL, 1980), ao definir os direitos e os deveres do imigrante, sem considerá-lo, como na Lei anterior, uma ameaça nacional. Há ainda na nova Lei a adequação do registro no texto do termo 'estrangeiro', para imigrante, ressignificando a percepção deste para pessoas que visitam o Brasil e não o caráter de 'invasores' (ILLES; SOUSA, 2012). Essa Lei ainda regulamenta a entrada e a permanência dos imigrantes no Brasil, instaurando uma política de migração mais aberta e flexível.

Há de se explicitar que povos que definem pela migração por razões diferentes das evidenciadas no Estatuto do Refugiado de 1966, como as vítimas de desastres naturais, não se enquadram na categoria de refugiados. Assim, haitianos, por exemplo, que tiveram a migração fomentada pelo terremoto, em 2010, encontraram dificuldades para serem acolhidos em outros países com base neste Estatuto. Segundo Sousa (2019[Web], grifo do autor),

[a] imigração haitiana no Brasil é resultado da instabilidade política e econômica vivida no Haiti. [...] Em 2010, o território haitiano sofreu um intenso abalo sísmico [...] cerca de três milhões de habitantes sofreram com as consequências dessa catástrofe. [...] O Haiti é um país que também sofre com a pobreza, por isso enfrenta dificuldades para se reconstruir a cada novo episódio de devastação.

Visando atender às necessidades migratórias dos haitianos, o Brasil passa a conceder a eles o direito à acolhida humanitária, pela Resolução Normativa $n^{\circ}$ 97, de 2012 (MILESI; MARINUCCI, 2017). No ano de 2013, a Resolução Normativa de $n^{\circ} 17$ estende esse direito aos sírios e, em 2017, aos venezuelanos. Essa consideração dos direitos do imigrante possibilita ao indivíduo não somente permanecer no lugar de destino, como também pleitear por acesso ao trabalho, saúde, educação, lazer, por fim, tornar-se cidadão com direitos e deveres. 
A esse respeito, Saladini (2011) e Wermuth (2020) ressaltam a busca por trabalho como sendo uma das principais razões de migração para o Brasil, embora a empregabilidade nem sempre seja consolidada na realidade do sujeito. São Bernardo (2016) ainda acrescenta que a possibilidade de uma vida melhor nesse 'novo mundo' acaba por fomentar esperanças de um acolhimento mais humanitário no local de destino.

A região Centro-Oeste, embora não seja a de maior prestígio econômico entre os territórios brasileiros, constitui-se como um dos destinos dos imigrantes que optam por se deslocarem para locais mais próximos da capital do país, entre estes, o estado de Goiás. Muitos desses imigrantes estabelecem-se em Goiânia ou cidades fronteiriças por entenderem que nessa zona urbana encontrarão condições de vida melhor.

Para essa perspectiva de melhoria, autores como Grosso (2010) e São Bernardo (2016) ressaltam a necessidade de aprendizagem da língua falada pela comunidade de destino. Saber essa língua oportuniza ao imigrante recursos para compreender como a sociedade receptora se estrutura e, a partir desse conhecimento, munir-se de um recurso que o auxiliará a ter voz para se posicionar perante a sociedade do território de destino.

Nessa acepção, torna-se relevante um processo de ensino-aprendizagem da língua portuguesa em uma vertente metodológica que considere o imigrante como um sujeito dotado de direitos e deveres no novo território. Nesse ponto de vista, defendemos o trabalho com o português na vertente de língua de acolhimento, tema que abordamos a seguir.

\section{Língua de acolhimento: uma abordagem de ensino humanitária}

A intensificação do processo de migração de pessoas em situação de vulnerabilidade desencadeia, nos contextos educacionais de Portugal, a adoção de uma abordagem de ensinoaprendizagem de língua portuguesa denominada de português como língua de acolhimento (PLAc). Segundo Grosso (2010), essa vertente busca considerar as enfáticas transformações sociais que permeiam contextos multiculturais, étnicos e multilinguísticos, em que a presença de imigrantes, em situação de vulnerabilidade social, faz-se cada vez mais presente.

No Brasil, segundo São Bernardo (2016), o uso da modalidade de ensino-aprendizagem de PLAc tem, igualmente, o objetivo de proporcionar aos imigrantes um acolhimento mais humanizado, pois essa forma de ensino-aprendizagem de português inclui o "prisma emocional e subjetivo da língua e a relação conflituosa presente no contato inicial do imigrante com a sociedade de acolhimento, a julgar pela situação de vulnerabilidade que essas pessoas enfrentam ao chegarem a um país estrangeiro" (SÃO BERNARDO, 2016, p. 66). 
O ensino de PLAc propõe, de maneira geral, transpor o viés pedagógico da aprendizagem meramente linguística, ressignificando a função comunicativa, para assumir o papel de ferramenta para o acolhimento afetivo, social e cultural do imigrante à sociedade recebedora. Nas palavras de Grosso $(2010$, p. 71), “a língua de acolhimento tem um saber fazer que contribui para uma interação real, a vida cotidiana, as condições de vida, as convenções sociais e outras que só podem ser compreendidas numa relação bidirecional".

Desse modo, o ensino de PLAc propõe auxiliar o imigrante a romper as barreiras linguísticas que impedem ou dificultam, muitas das vezes, o seu acesso a atividades cotidianas, geralmente consideradas descomplicadas para falantes fluentes da língua de comunicação da comunidade local, como fazer compras de alimentos, receber um atendimento médico, realizar uma entrevista de trabalho, ou, em um contexto de sala de aula, dizer ao professor que não compreendeu um determinado conteúdo. Essas ações, embora possam ser descritas como corriqueiras, são atividades indispensáveis para a sobrevivência do imigrante no país acolhedor e, sem o conhecimento da língua, difíceis de serem realizadas pelos próprios imigrantes (GROSSO, 2010; SÃO BERNARDO, 2016).

Pelo viés do país que acolhe, no caso do Brasil, o Art. $4^{\circ}$ da Lei de Migração n. ${ }^{\circ}$ 13.445/2017 garante ao imigrante o direito à educação pública, vedada a discriminação em razão da nacionalidade e da condição migratória. No entanto, o Brasil não possui oficialmente uma política linguística que assegure o direito à aprendizagem da língua portuguesa, tampouco na proposta de língua de acolhimento (COSTA; SILVA, 2018). Além disso, os imigrantes, em fase de educação básica, também não possuem garantias na legislação de que a escola lhes apoiará na aprendizagem de português, tampouco dos outros conteúdos escolares, dos quais a língua é a ferramenta de instrução e, menos ainda, na integração deles à comunidade escolar.

Nessa perspectiva, os imigrantes adolescentes podem se sentir inibidos e, até mesmo, distanciar-se da comunidade escolar por não encontrar, nesse contexto, um ensinoaprendizagem que primeiramente lhes acolha e os reconheça como sujeitos recém-chegados, ainda deslocados da realidade escolar.

De acordo com São Bernardo (2016), ensinar língua de acolhimento para imigrantes, especialmente em situação de vulnerabilidade social, envolve uma ação mediadora, acolhedora e afetiva, que está além do viés linguístico e cultural. Em se tratando de imigrantes adolescentes, ainda precisam ser consideradas as relações interpessoais deles com a comunidade escolar, especialmente colegas de sala de aula e professores. Para tanto, faz-se necessário considerar que ao chegar no Brasil o imigrante adolescente está sob forte pressão emocional, na maioria das vezes sentindo-se deslocado, vulnerável e até mesmo obrigado, por decisão de sua família, 
a permanecer no novo espaço, com o qual não possui familiaridade e este espaço inclui a escola regular de ensino fundamental e médio.

Além do mais, em contexto de ensino de línguas, especialmente para imigrantes, tornase fundamental valorizar as identidades multiculturais presentes em sala de aula, com vistas a promover a integração do sujeito à comunidade do país de destino, auxiliando-o em seu processo emancipatório. Aplicando tal construto ao contexto educacional, podemos afirmar que, para os alunos adolescentes, o processo de emancipação, muitas vezes, iniciou-se no país de origem e foi interrompido pela necessidade de acompanhar a família no deslocamento migratório.

À vista disso, o ensino de PLAc tem sido ofertado de forma extracurricular, muitas vezes por meio de trabalhos voluntários, fomentados por instituições civis e governamentais, como Universidades e Institutos Federais em conjunto com a sociedade civil, como o projeto de extensão ao qual este estudo se vincula. São iniciativas assim que vão acolhendo o imigrante, possibilitando-o mais um meio para a integração à comunidade recebedora, a qual, na nossa opinião, deveria ser sempre acolhedora.

Para melhor conhecer os imigrantes e a professora que atuaram na perspectiva de PLAc, bem como outros elementos constituintes deste estudo, apresentamos, no próximo item, a metodologia desta pesquisa.

\section{Metodologia}

Este estudo segue o paradigma qualitativo de pesquisa, constituindo-se como um estudo de caso (ANDRÉ, 1984). O contexto desta investigação é composto por uma turma de PLAc, denominada de 'Turma dos adolescentes', cujas aulas ocorreram aos sábados, com a duração de 2 horas, no segundo semestre de 2018 (2018/2) e no primeiro semestre de 2019 (2019/1), em um projeto de extensão do Instituto Federal de Goiás (IFG) - Campus Goiânia.

É importante ressaltar que fizeram parte do todo desse projeto, neste período, cerca de 60 alunos imigrantes, os quais foram distribuídos em diferentes turmas, segundo a idade, nível de conhecimento de português e tempo de moradia no Brasil. A 'Turma dos Adolescentes' possuía 5 alunos haitianos, dos quais três são os participantes focais deste estudo, conforme apresenta o quadro 1, a seguir: 
Quadro 1 - Os imigrantes haitianos adolescentes

\begin{tabular}{|c|c|c|c|c|c|}
\hline \multicolumn{3}{|c|}{ Participantes - 2018/2 } & \multicolumn{3}{c|}{ Participantes - 2019/1 } \\
\hline Pseudônimo & $\begin{array}{c}\text { Idade } \\
\text { (anos) }\end{array}$ & $\begin{array}{c}\text { Escolaridade } \\
\text { Ensino Fundamental (EF) }\end{array}$ & Pseudônimo & $\begin{array}{c}\text { Idade } \\
\text { (anos) }\end{array}$ & $\begin{array}{c}\text { Escolaridade } \\
\text { Ensino Fundamental (EF) }\end{array}$ \\
\hline Mel & 13 & $8^{\circ} \mathrm{EF}$ & Mel & 14 anos & $9^{\circ}$ ano \\
\hline Nilo & 11 & $6^{\circ} \mathrm{EF}$ & Nilo & 12 anos & $7^{\circ}$ ano \\
\hline Mar & 11 & $5^{\circ} \mathrm{EF}$ & \multicolumn{3}{|c}{-} \\
\hline
\end{tabular}

Fonte: Acervo das autoras

A professora dos adolescentes também é participante desta pesquisa e está identificada pelo pseudônimo Any. À época do estudo, ela era aluna de Licenciatura em Letras: Língua Portuguesa, cursando, em 2018, o quinto período e, em 2019, o sexto, igualmente no IFG Campus Goiânia.

Para a geração de dados, foram utilizados trechos de plano de aula, material didático, tarefas escritas realizadas pelos alunos, um questionário impresso e o diário reflexivo da professora Any. Esses dados foram utilizados na sua forma original, sem adequações à norma

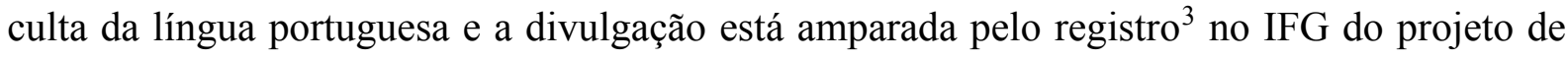
extensão, ao qual este estudo se vincula. A análise foi desenvolvida visando apresentar o modo como a abordagem de ensino-aprendizagem na vertente PLAc foi trabalhada com os alunos da ‘Turma dos Adolescentes', tendo como propósito principal o acolhimento.

\section{Discussão dos dados}

Considerando que as aulas de PLAc foram direcionadas para alunos adolescentes haitianos, nossas principais indagações referiam-se a como fazer uso do ensino da língua portuguesa para aprimorar a oralidade e a escrita dos aprendizes e ainda lhes proporcionar mecanismos para a integração à comunidade de acolhimento. Buscamos, portanto, conhecê-los. Para isso, perguntamos-lhes sobre os motivos que levaram as famílias deles a migrarem para o Brasil. As figuras 1 e 2 apresentam os relatos de Nilo e Mel.

${ }^{3}$ Projeto aprovado pelo IFG sob o registro no SUAP n ${ }^{\circ} 23373.001757 / 2020-30$. 
Figura 1 - Questionário impresso - Nilo

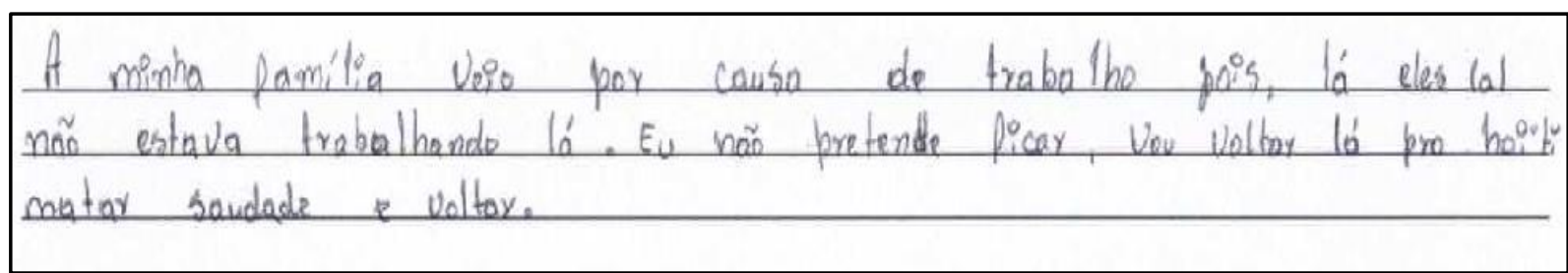

Fonte: Acervo das autoras

Figura 2 - Questionário impresso - Mel

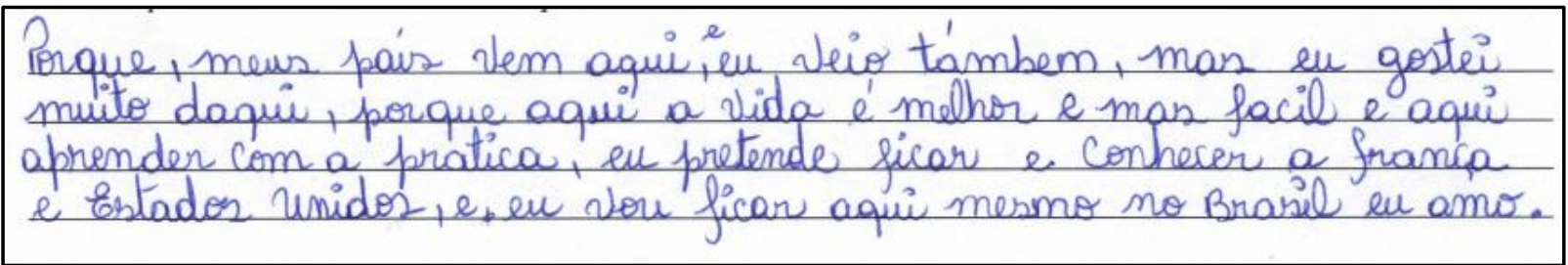

Fonte: Acervo das autoras

O relato de Nilo traz a questão do desemprego no país de origem como razão do deslocamento de sua família do Haiti para o Brasil. Mel, por sua vez, já afirma querer ficar no Brasil e expandir seus horizontes para outros países. Para ela, o Brasil representa um local de mais oportunidades para sua família.

A esperança depositada no país acolhedor, segundo Saladini (2011), São Bernardo (2016) e Wermuth (2020), está associada ao desemprego que muitos haitianos enfrentam em razão dos problemas de ordem social e econômica, que assolam o Haiti há décadas, e que foram agravadas após o terremoto ocorrido em 2010. Assim, muitas famílias, como as de Nilo e Mel, deixaram a terra natal acreditando que haveria oportunidades de emprego no território de destino. A essas oportunidades somam-se a esperança na oferta de formação escolar, principalmente para as crianças e os adolescentes.

Em vista disso, as aulas de PLAc foram pautadas no âmbito da construção coletiva, respeitando a diversidade linguística e cultural dos adolescentes haitianos, buscando sempre uma interação em que eles se sentissem confortáveis e seguros para expressar os assuntos de interesse deles, suas ansiedades e alegrias. Por conseguinte, as temáticas das aulas eram selecionadas e desenvolvidas a partir das conversas com os alunos.

O tema relacionado ao esporte futebol, como ilustrado na figura 3, por exemplo, foi um tema escolhido pelos alunos e trabalhado por meio do gênero 'charge'. Este gênero textual também estava sendo abordado no contexto da escola regular para alguns dos alunos, portanto queríamos discutir algo que eles gostavam ao mesmo tempo em que os auxiliávamos na melhor compreensão dos conteúdos escolares. 
Quadro 2 - Trecho do plano. 29/10/2018

\begin{tabular}{|l|l|l|}
\hline $\begin{array}{l}\text { Atividade de } \\
\text { compreensão de } \\
\text { texto. }\end{array}$ & $\begin{array}{l}10^{\prime}-\text { Averiguando a } \\
\text { aprendizagem }\end{array}$ & $\begin{array}{l}\text { Os alunos, em duplas, deverão explicar aos } \\
\text { outros colegas o que entenderam das charges } \\
\text { (se reconhecem algum jogador, o contexto e } \\
\text { a mensagem da charge). }\end{array}$ \\
\hline
\end{tabular}

Fonte: Acervo das autoras

Figura 3 - Material didático - Charge

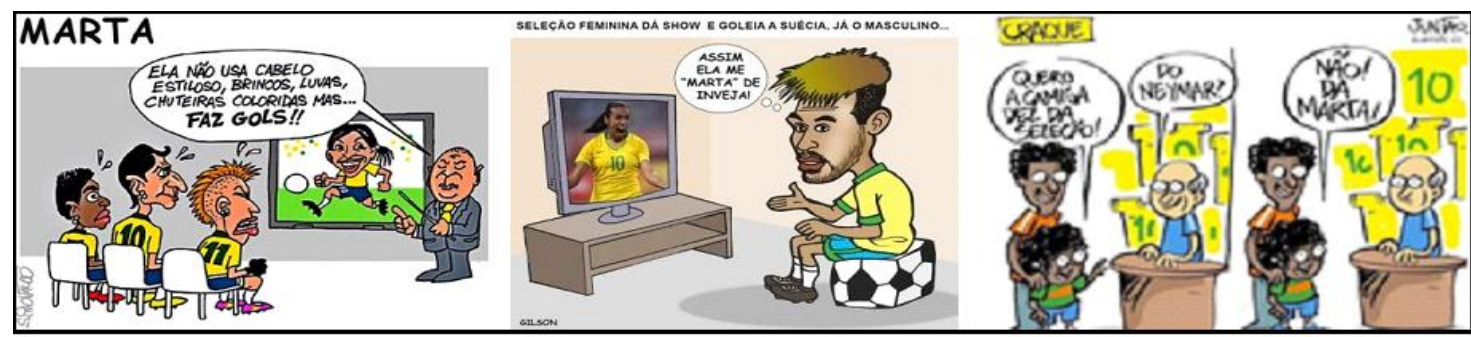

Fonte: Acervo das autoras

[Diário reflexivo. Any, $5^{\circ}$ periodo de letras, 2018/2]

Esta proposta de aula nos fez entender como o vínculo construído e a empatia entre aluno e professor é importante para a construção de conhecimento mútuo. Neste dia podemos ver o contraste entre as culturas brasileira e Haitiana. Eu fiquei surpreendida com a paixão deles pelo futebol, bem parecido com os brasileiros, não imaginava que no Haiti as meninas também gostavam e jogavam futebol.

Durante a aula, notamos a euforia dos alunos. O tema 'futebol' realmente foi o fator motivador do interesse deles. Todos foram muito participativos e demonstraram conhecer os personagens da charge, identificando-os e nomeando-os corretamente. Essa aula fez com que os alunos resgatassem suas memórias afetivas e contassem-nos sobre suas experiências no Haiti. Eles nos relataram que nesse país o futebol, tal como no Brasil, também é uma das brincadeiras prediletas praticadas pelos adolescentes.

Nessa aula, a proposta da abordagem PLAc se materializou na relação de afetividade que conduziu a troca cultural entre os alunos e a professora. Eles compartilharam conosco suas lembranças, fazendo delas razões para rir, contar histórias e conectar o Haiti ao Brasil de forma positiva, amenizando, na nossa visão, a saudade do país de origem. A intenção de auxiliar os alunos com os conteúdos da escola regular tornou-se um verdadeiro momento de acolhimento nos moldes defendidos pelos estudiosos da área de PLAc. Grosso (2010) e São Bernardo (2016) reiteram ser PLAc muito mais que uma abordagem de ensino de conteúdos linguísticos, pois engloba aspectos relacionados à emoção e à subjetividade dos falantes.

A tarefa realizada a partir da aula sobre o tema 'futebol', objetivava o trabalho com questões de escrita, pois a oralidade dos alunos apresentava um nível muito bom de fluência. 
Para tanto, elaboramos uma tarefa de produção de sentenças a partir de palavras extraídas por eles do contexto do futebol, como 'craque', 'jogador' e 'bandeira', como podemos ver nos registros das figuras 4 e 5 .

Figura 4 - Tarefa escrita - Mar

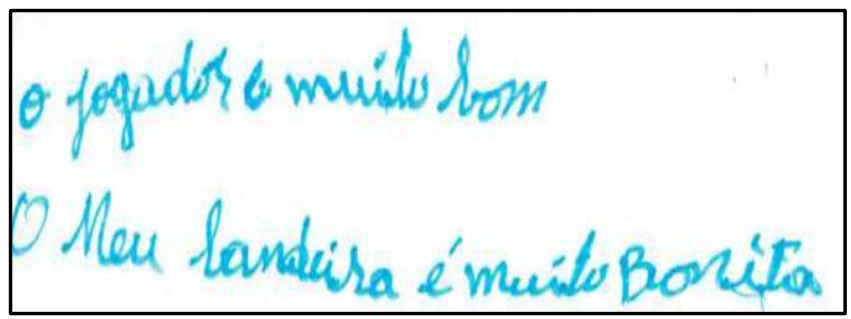

Fonte: Acervo das autoras

Figura 5 - Tarefa escrita - Mel

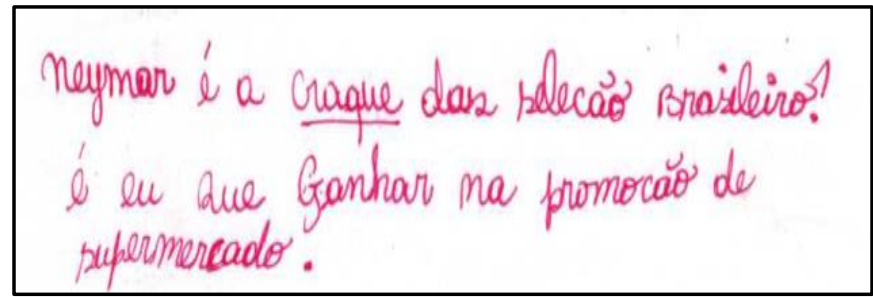

Fonte: Acervo das autoras

Percebemos que nas sentenças havia uma inversão no uso do feminino e masculino e alguns outros desvios da norma escrita, como concordância verbal. A nossa intervenção foi feita solicitando aos próprios alunos que lessem seus textos e verificassem se havia algo ‘estranho’ na estruturação das sentenças. Eles, na maioria dos casos, identificaram os problemas e fizeram a correção oral.

Para ampliar essa correção, anotamos no quadro as frases que estavam inadequadas e perguntamos mais uma vez aos alunos onde estavam os desvios linguísticos e o porquê do problema. Os alunos com maior habilidade na escrita auxiliaram os colegas com menos conhecimento, dando sugestões de correção e de explicações das causas dos erros. Essa interação intensificou o uso da oralidade, pois eles conversaram bastante durante a correção e ainda lhes proporcionou verificar as diferenças entre uso escrito e oral da língua portuguesa, em uma perspectiva positiva de correção, em que os alunos foram os protagonistas de suas aprendizagens, respeitados e incluídos no desenvolvimento do conteúdo.

Demos seguimento à aula de PLAc, com a apresentação do gênero textual 'história em quadrinho' (HQ), utilizando como suporte o trabalho com gibis da 'Turma da Mônica', escritos 
por Maurício de Souza. Nosso objetivo era promover a leitura, apresentar o gênero HQ e ampliar o conhecimento dos alunos sobre essa modalidade de língua escrita, como nos mostra o recorte do plano de aula da figura 6.

Figura 6 - Trecho do plano da aula. 06/04/19

\begin{tabular}{|c|c|c|}
\hline $\begin{array}{l}\text { 1- Leitura } \\
\text { verbal e } \\
\text { não verbal. } \\
\text { Interpretaçã } \\
\text { o de texto. }\end{array}$ & $50^{\prime}$ & $\begin{array}{l}\text { COMPREENDENDO O GÊNERO GIBI } \\
\begin{array}{l}\text { 4. Perguntar aos alunos se: } \\
\text { - } \text { - jabem o que é 'gibi"' } \\
\text { - gostam gibis? } \\
\text { - qual(is) gibi já leram? } \\
\text { Distribuiremos um gibi para cada aluno para que eles possam folear em um } \\
\text { primeiro momento, estimulando a percepção das principais caracteristicas } \\
\text { do gênero história em quadrinhos. } \\
\text { - Dizer para eles que podem escolher uma história para ler (dar cerca } \\
\text { de } 30 \text { minutos para a leitura). Monitorar para controlar se haverá }\end{array}\end{array}$ \\
\hline
\end{tabular}

Fonte: Acervo das autoras

Realizamos, nesta aula, a leitura coletiva de HQs e pudemos perceber que alguns alunos apresentavam dificuldades na pronúncia de algumas palavras. Constatamos também a necessidade de, além de incentivar a leitura para aprimorar a pronúncia, elaborar uma tarefa que promovesse o uso de pontuação e acentuação.

A tarefa elaborada e realizada em sala de aula, desta vez no laboratório de informática, solicitava aos alunos que assistissem ao vídeo 'Casa na Árvore', da Turma da Mônica, disponível na plataforma YouTube e depois interpretassem o contexto da história e apostassem, com base nessa interpretação, no que eles consideravam verdadeiro, como podemos ver na figura 9 . 
Figura 9- Tarefa escrita - Mel

\begin{tabular}{|c|c|c|c|c|}
\hline \multicolumn{5}{|c|}{ 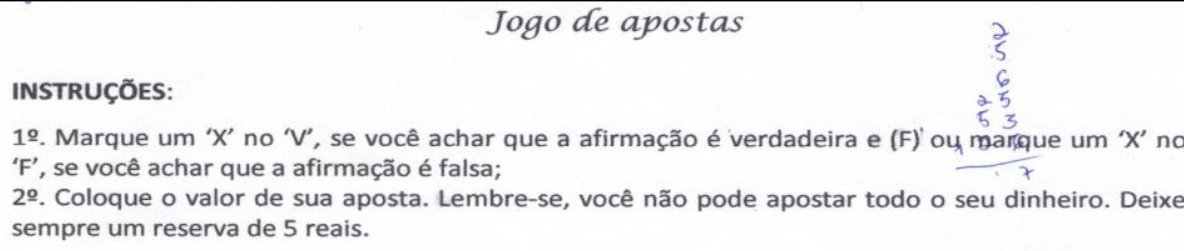 } \\
\hline & & V & $\mathrm{F}$ & $\begin{array}{l}\text { Valor da } \\
\text { aposta }\end{array}$ \\
\hline 1 & $\begin{array}{l}\text { Construir a casa na árvore é um sonho apenas de um dos } \\
\text { meninos. }\end{array}$ & & $x$ & क 2 \\
\hline 2 & $\begin{array}{l}\text { Os meninos decidem construir a casa embaixo e depois levar para } \\
\text { cima da árvore. }\end{array}$ & $x$ & $\therefore$ & $\$ R 5$ \\
\hline 3 & A casa será um lugar para os meninos dormirem. & & $x$ & $\$ S R$ \\
\hline 4 & $\begin{array}{l}\text { Cebolinha, o menino de camisa verde, acha que a casa parece } \\
\text { uma casinha de cachorro ou uma casinha de passarinho. }\end{array}$ & $X$ & & $5 R 25$ \\
\hline 5 & Os dois meninos se escondem da menina dentro da casa. & $x$ & & SR $5 B$ \\
\hline 6 & Mônica sobe na árvore e prende a casa nos galhos. & & $x$ & $\$ R 126$ \\
\hline & $\begin{array}{r}126 \\
126 \\
252\end{array}$ & & & 252 \\
\hline
\end{tabular}

Fonte: Acervo das autoras

Mantivemos a linha do trabalho com narrativas, agora por meio de vídeo, e retomamos a perspectiva das HQs. Os alunos puderam, então, ouvir português no formato de diálogos, em que as entonações marcavam as pausas de pontuação. Eles ainda foram motivados a interpretar o texto e a realizar somas e subtrações, atuando, portanto, no campo das exatas, área que eles nos solicitaram auxílio, visto que estavam tendo dificuldades com as tarefas escolares de matemática.

Essa perspectiva de unir o ensino de PLAc ao da matemática mostrou-nos que o acolhimento por meio da língua de fato ultrapassa questões linguísticas não somente por entrar no campo da afetividade e do empoderamento do sujeito como membro da comunidade de acolhimento, mas principalmente por possibilitar ao imigrante construir a sua própria história nessa nova sociedade, desejando que ele de fato seja acolhido como um sujeito que pertence a este novo território.

Nesse âmbito, a perspectiva pedagógica na modalidade PLAc consolida-se em uma via de mão dupla, em que a interação entre os sujeitos que aprendem e os sujeitos que ensinam comungam para a construção de um sujeito político, histórico, social e cultural consciente de seu lugar na comunidade acolhedora e, ainda, de seus direitos de se (re)construir dentro destes espaços. É nesse viés que apresentamos nossas considerações finais. 


\section{Considerações finais}

O trabalho desenvolvido durante as aulas de PLAc comprovou que ensinar português para imigrantes de fato envolve mais do que o ensino da língua, pois, em um âmbito maior, estamos sempre em uma busca de meios para atender às necessidades mais urgentes do imigrante, as quais, no caso dos adolescentes participantes deste estudo, estão muito ligadas ao âmbito da afetividade.

Seguindo a proposição da integração do imigrante ao contexto escolar e, por extensão, à comunidade goiana, buscamos trabalhar os conteúdos e propor tarefas fundamentadas no interesse e nas necessidades dos alunos, o que foi um fator motivador da aprendizagem e promotor do acolhimento. Os alunos puderam expressar suas dificuldades com os conteúdos das escolas regulares e, ainda, contar suas histórias de vida em uma relação de confiança e empatia entre eles e a professora.

Quanto à aprendizagem de português pelos alunos adolescentes, os dados deste estudo permitem-nos afirmar que o ensino de PLAc proporcionou-lhes oportunidades de desenvolver e aperfeiçoar a oralidade e aprimorar um pouco mais a escrita. Para a professora, o amadurecimento pedagógico e didático aconteceu na constante inter-relação entre teoria e prática, construída nas interações entre ela e os alunos. O conceito de acolhimento ampliou-se para o carinho recebido dos alunos, acolher tornou-se ser acolhida. Esse fato constituiu-se em um princípio que será transposto para a vida profissional, sejam em aulas de PLAc com alunos imigrantes ou em aulas de português como língua materna, com alunos brasileiros.

Por fim, o ensino de PLAc traz à tona a urgente necessidade do amparo aos imigrantes por parte das autoridades governamentais e legais, entre elas, as que podem efetivar as políticas linguísticas de ensino de português para falantes de outras línguas residindo no Brasil. Assim, alunos, como os participantes deste estudo, terão seus direitos à aprendizagem de português e à manutenção de suas outras línguas oficialmente garantidos. Destarte, brasileiros terão oportunidades de expandir seus horizontes culturais e linguísticos e haitianos se sentirão como parte deste país, famoso por belezas naturais e, quem sabe, por um acolhimento verdadeiramente humanitário. 


\section{REFERÊNCIAS}

ACNUR. Relatório global do ACNUR revela deslocamento forçado de $1 \%$ da

humanidade. 2020a. Disponível em: https://www.acnur.org/portugues/2020/06/18/relatorioglobal-do-acnur-revela-deslocamento-forcado-de-1-da-humanidade/. Acesso em: 13 fev. 2021.

ACNUR. Refugiados. 2020b. Disponível em: https://www.acnur.org/portugues/quemajudamos/refugiados/. Acesso em: 13 fev. 2021.

ANDRÉ, M. E. D. A. Estudo de caso: seu potencial na educação. Cadernos de Pesquisa, São Paulo, v. 49, p. 51-14, 1984.

BRASIL. Lei n. 13.445, de 24 de maio de 2017. Institui a Lei de Migração. Brasília, 25 maio. 2017. Disponível em: http://www.planalto.gov.br/ccivil_03/_ato2015-

2018/2017/lei/L13445.htm. Acesso em: 15 maio 2019.

BRASIL. Lei n. 6.815, de 19 de agosto de 1980. Define a situação jurídica do estrangeiro no Brasil, cria o Conselho Nacional de Imigração. Brasília, DF, 21 ago. 1980. Disponível em: http://www.planalto.gov.br/ccivil_03/leis/16815.htm. Acesso em: 15 maio 2019.

COSTA, E. J; SILVA, F. C. Legislação migratória e português como língua de acolhimento: reflexões sobre políticas linguísticas e lingua(gem). Revista de Divulgação Científica em Língua Portuguesa, Linguística e Literatura, ano 14, n. 23, p. 598-612, 2018. ISSN 18075193. Disponível em: http://minasfazciencia.com.br/wpcontent/uploads/2019/02/artigoLetraMagna.pdf. Acesso em: 10 fev. 2021.

FERNANDES, D.; FARIA, A. V. de. O visto humanitário como resposta ao pedido de refúgio dos haitianos. Revista Brasileira de Estudos de População, Belo Horizonte, v. 34, n. 1, p. 145-161, jan./abr. 2017. Disponível em: https://www.scielo.br/pdf/rbepop/v34n1/0102-3098rbepop-34-01-00145.pdf. Acesso em: 13 fev. 2021.

GROSSO, M. J. Língua de acolhimento, língua de integração. Horizontes de Linguística Aplicada, Belo Horizonte, v. 9, n. 2, p. 61-77, 2010. Disponível em: http://periodicos.unb.br/index.php/horizontesla/article/view/886/771. Acesso em: 01 jan. 2021.

ILLES, P.; SOUSA, R. Todos somos migrantes: análise crítica da atual política migratória brasileira. Frente Brasil Popular - CDHIC, 2012. Disponível em:

http://cdhic.cut.org.br/imprimir/news/7e1df0f7e671fb26ee2fc55793b714b0/. Acesso em: 16 fev. 2021.

MILESI, R.; MARINUCCI, R. Apontamentos sobre Migrações e Refúgio no Contexto Internacional e Nacional. In: JUBILUT, L. L.; GODOY, G. G. (org.). Refúgio no Brasil: Comentários à Lei 9.474/97. São Paulo: Quartier Latin/ACNUR, 2017. p. 27-40. Disponível em: https://www.acnur.org/portugues/wpcontent/uploads/2018/02/Ref\%C3\%BAgio-noBrasil-Coment\%C3\%A1rios-\%C3\%A0-lei-9.474-97-2017.pdf. Acesso em: 11 fev. 2021.

ONU. Assembleia Geral das Nações Unidas. Convenção relativa ao Estatuto dos

Refugiados. 1951. Disponível em: http://www.direitoshumanos.usp.br/index.php/Refugiados- 
Asilos-Nacionalidades-e-Ap\%C3\%A1tridas/convencao-de-genebra-relativa-ao-estatuto-dosrefugiados.html. Acesso em: 05 dez. 2020.

ONU. Assembleia Geral das Nações Unidas. Convenção relativa ao Estatuto dos

Refugiados. 1967. Disponível em:

https://www.acnur.org/fileadmin/Documentos/portugues/BDL/Convencao_relativa_ao_Estatu to_dos_Refugiados.pdf. Acesso em: 05 dez. 2020.

SALADINI, A. P. S. Trabalho e imigração: os direitos sociais do trabalhador imigrante sob a perspectiva dos direitos fundamentais. 2011. 285 f. Dissertação (Mestrado em Ciência Jurídica) - Centro de Ciências Sociais Aplicadas do Campus de Jacarezinho da Universidade Estadual do Norte do Paraná, Jacarezinho, 2018. Disponível em: https://uenp.edu.br/posdireito-teses-dissertacoes-defendidas/direito-dissertacoes/1964-ana-paula-sefrin-saladini/file. Acesso em: 18 jan. 2021.

SÃO BERNARDO, M. A. Português como língua de acolhimento: um estudo com imigrantes e pessoas em situação de refúgio no Brasil. 2016. 206 f. Tese (Doutorado em Linguística) - Universidade Federal de São Carlos, São Carlos, 2016. Disponível em: https://repositorio.ufscar.br/handle/ufscar/8126?show=full. Acesso em: 27 maio 2019.

SOUSA, R. Imigração haitiana no Brasil. Mundo Educação, p. 1-5, 2019. Disponível em: https://mundoeducacao.uol.com.br/geografia/imigracao-haitiana-no-brasil.htm. Acesso em: 13 maio. 2019.

WERMUTH, M. Â. D. As políticas migratórias brasileiras do século XIX ao século XXI: uma leitura biopolítica do movimento pendular entre democracia e autoritarismo. Revista Direito e Práxis, Rio de Janeiro, v. 11, n. 4, p. 2330-2358, 2020. DOI: 10.1590/21798966/2020/45137| ISSN: 2179-8966

\section{Como referenciar este artigo}

MORAIS, D. G; SILVA, S. V. O ensino-aprendizagem de PLAc para adolescentes haitianos. Rev. EntreLínguas, Araraquara, v. 7, n. esp. 6, e021148, dez. 2021. e-ISSN: 2447-3529. DOI: https://doi.org/10.29051/el.v7iesp.6.15439

Submetido em: 30/08/2021

Revisões requeridas em: 16/10/2021

Aprovado em: 29/11/2021

Publicado em: 28/12/2021 